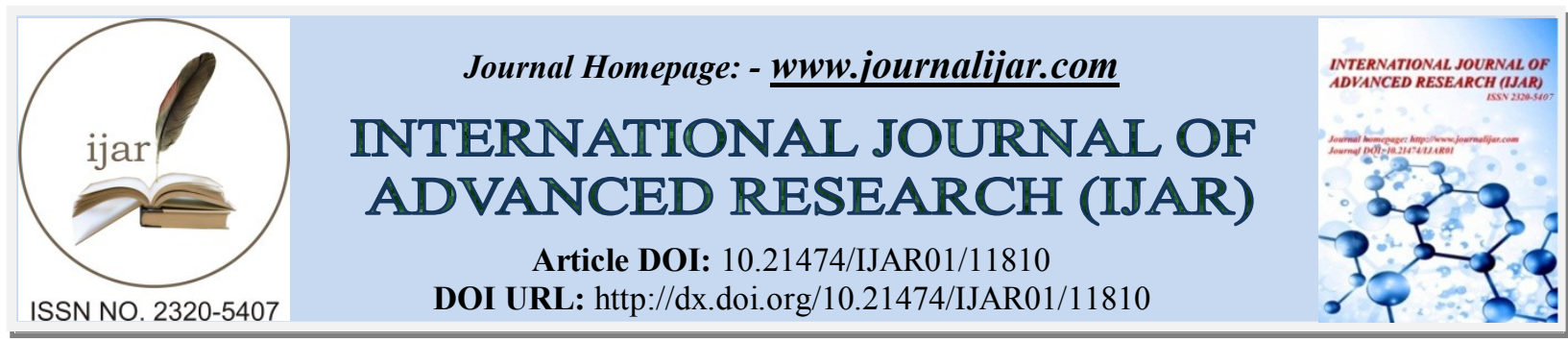

RESEARCH ARTICLE

\title{
AN ANALYSIS AND SIGNIFICANCE OF IMMUNOHISTOCHEMISTRY ER, PR AND HER2 TESTING FOR BREAST MALIGNANCY IN A TERTIARY CARE CENTER
}

\author{
Dr. G. Jeyanthi ${ }^{1}$, Dr. S. Malliga ${ }^{1}$ and Dr. K. Rani ${ }^{2}$ \\ 1. Associate Professor, Department Of Pathology, Madurai Medical College. \\ 2. Professor, Department Of Pathology, Madurai Medical College.
}

\section{Manuscript Info}

.........................

Manuscript History

Received: 26 July 2020

Final Accepted: 31 August 2020

Published: September 2020

Key words:-

Invasive Carcinoma Breast, Immunohistochemistry ( IHC), Estrogen Receptor (ER) Progesteron Receptor (PR) , Human Epidermal Growth Factor Receptor ( HER-2/neu), Gold Standard

\section{Abstract}

Background: A significant development in the Breast malignancy, the expression of Hormone receptors in the tumor cells for the management and prognosis.

Aim of Study : This study was conducted to correlate Immunohistochemical expression of markers such as estrogen receptor( ER), progesterone receptor (PR ), and Her-2/neu with clinical mainly age, sex and Histopathological parameters .

Materials and Methods: This prospective study was done at the tertiary care hospital from January 2019 to January 2020. 296 cases of Breast malignancy were studied. Immunohistochemistry (IHC) for ER, PR, and Her-2/neu was performed. The laboratory reporting was done according to the standard scoring system from CAP protocol 2019.

Results: According to the molecular basis of Breast tumor, the ER positive and Her-2 Negative was observed in $24.6 \%$ ( 73/296) cases, ER Positive and Her-2/neu Positive in 22.9 \% ( 68/296) cases, whereas ER negative and Her-2 /neu positive in $21.6 \%$ ( 64/296) cases. Triple marker (ER , PR and Her-2) negative cases were seen in $23.9 \%$ ( 71/296). Triple marker positive cases were $6.75 \%$ ( 20/296).

Conclusion: IHC markers studies in Breast malignancy is still gold standard for treating the patients and prognostic aspect.

Copy Right, IJAR, 2020,. All rights reserved.

\section{Introduction:-}

Breast malignancy is the most common malignant tumor and the second most common cause of carcinoma death in women, with more than 1.7 million cases occurring worldwide annually.[1] The large majority of breast cancers are detected during the post menopausal years. However, breast cancer can develop at any age from childhood to old age. [1] Hormone receptor studies such as estrogen receptor (ER), progesterone receptor (PR), and human epidermal growth factor receptor-2(HER -2/neu) are routinely done in breast carcinoma.[2] A correlation between the presence of hormone receptors in the tumor and response to hormonal therapy and chemotherapy is a significant development in the breast carcinoma management.[3].In our study analysis of receptor studies and expression pattern pertaining to the age group in our zone.

Corresponding Author:- Dr. G. Jeyanthi

Address:- Associate Professor, Department Of Pathology, Madurai Medical College. 


\section{Materials And Methods:-}

In our study we included all cases of breast malignancy (296 cases) for one year period (from January 2019-January 2020) received from surgical department. Clinical parameters of patients such as age, sex and parity were taken. All the modified radical mastectomy specimens and tru cut biopsy specimens were submitted for histopathological processing. All the tissues were fixed in $10 \%$ buffered formalin immediately, after sections were taken from tumor and biopsy were submitted for processing. Routine haematoxylin and eosin staining was performed for histopathological diagnosis. Histopathological type of the tumor were classified according to WHO.

Immunohistochemistry (IHC) for ER ,PR and HER2/neu were performed in the respective block of paraffin embedded tumor tissue. 4 micrometer thick sections were taken on poly-L-lysin coated slides and submitted for IHC. After antigen retrieval was done using citrate buffer at $\mathrm{pH} 2.5$ for hormone receptor and $\mathrm{pH} 6$ for HER2/neu. They were then incubated for 30 minutes with primary monoclonal antibodies against HER2/new (DAKO, clone 124,1:100), ER (DAKO, clone 1D5,1/25) and PR (DAKO, clone PgR636, 1/50) followed by incubation with biotin - secondary antibodies. The streptavidine -peroxidase complex was visualized using di amino benzidine as a chromogenic substrate. The normal breast ducts served as a internal positive control for ER/PR. Breast malignancy with known HER2 /neu over expression served as an external positive control for HER2/neu staining. For interpretation of ER/PR staining the following Allred system of scoring method was used as in Cap protocol

Table 1:- Allred score for Estrogen and Progesterone Receptor evaluation:

\begin{tabular}{|l|l|}
\hline 0,2 & Negative \\
\hline $3,4,5,6,7,8$ & Positive \\
\hline
\end{tabular}

Table 2:- For interpretation of HER2/neu staining the following methods were used.

The $\mathrm{H}$ score is determined by multiplying the percentage of cells demonstrating each intensity (scored from 0 to 3 ) and adding the results. There are 300 possible values. In this system, $<1 \%$ positive cells is considered to be a negative result.

\begin{tabular}{|c|c|c|}
\hline Calculation of H Score & \multicolumn{2}{|c|}{} \\
\hline & Percentage of cells & Values multiplied \\
\hline Cells with no signal & 0 & $\% x 0=0$ \\
\hline Cells with weak signal & 1 & $\% x 1=1$ \\
\hline Cells with moderate signal & 2 & $\% \times 2=2$ \\
\hline Cells with strong signal & 3 & $\% x 3=3$ \\
\hline
\end{tabular}

\section{Results:-}

This study group comprised of a total 296 breast malignancy. Mostly occurred in females (294/296) for about 99\% and male (2/296) for about $1 \%$.Out of 296 cases 95 cases were between $40-50$ years of age followed by 84 cases from 51-60 years of age group.

Table 3:- Age wise distribution of cases.

\begin{tabular}{|l|l|l|}
\hline Age in years) & Total cases & Percentage \\
\hline $20-30$ & 8 & $2.7 \%$ \\
\hline $31-40$ & 53 & $18 \%$ \\
\hline $41-50$ & 95 & $32 \%$ \\
\hline $51-60$ & 84 & $28.3 \%$ \\
\hline $61-70$ & 41 & $13.8 \%$ \\
\hline $71-80$ & 14 & $4.7 \%$ \\
\hline $81-90$ & 1 & $0.1 \%$ \\
\hline
\end{tabular}

The most common histological type was invasive carcinoma breast no special type 290/296(97.9\%). Next stands the invasive papillary carcinoma 4/296(1.3\%), the carcinoma with medullary feature 1 case and mucinous carcinoma, 1 case.

According to the molecular classification of breast malignancy, the IHC expressing profile pattern was analyzed.[Table 4], [Figure 3] 
Table 4:- Results of the Molecular classification of ER/PR and HER2/neu markers.

\begin{tabular}{|c|c|c|}
\hline Markers & Number of cases & Percentage \\
\hline ER +ve HER2 -ve & 73 & $24.6 \%$ \\
\hline ER+ve HER2 +ve & 68 & $22.9 \%$ \\
\hline ER-ve HER2+ & 64 & $21.6 \%$ \\
\hline Triple negative & 71 & $23.9 \%$ \\
\hline Triple positive & 20 & $6.75 \%$ \\
\hline Total & 296 & \\
\hline
\end{tabular}

Fig 3:- Distribution of marker results.

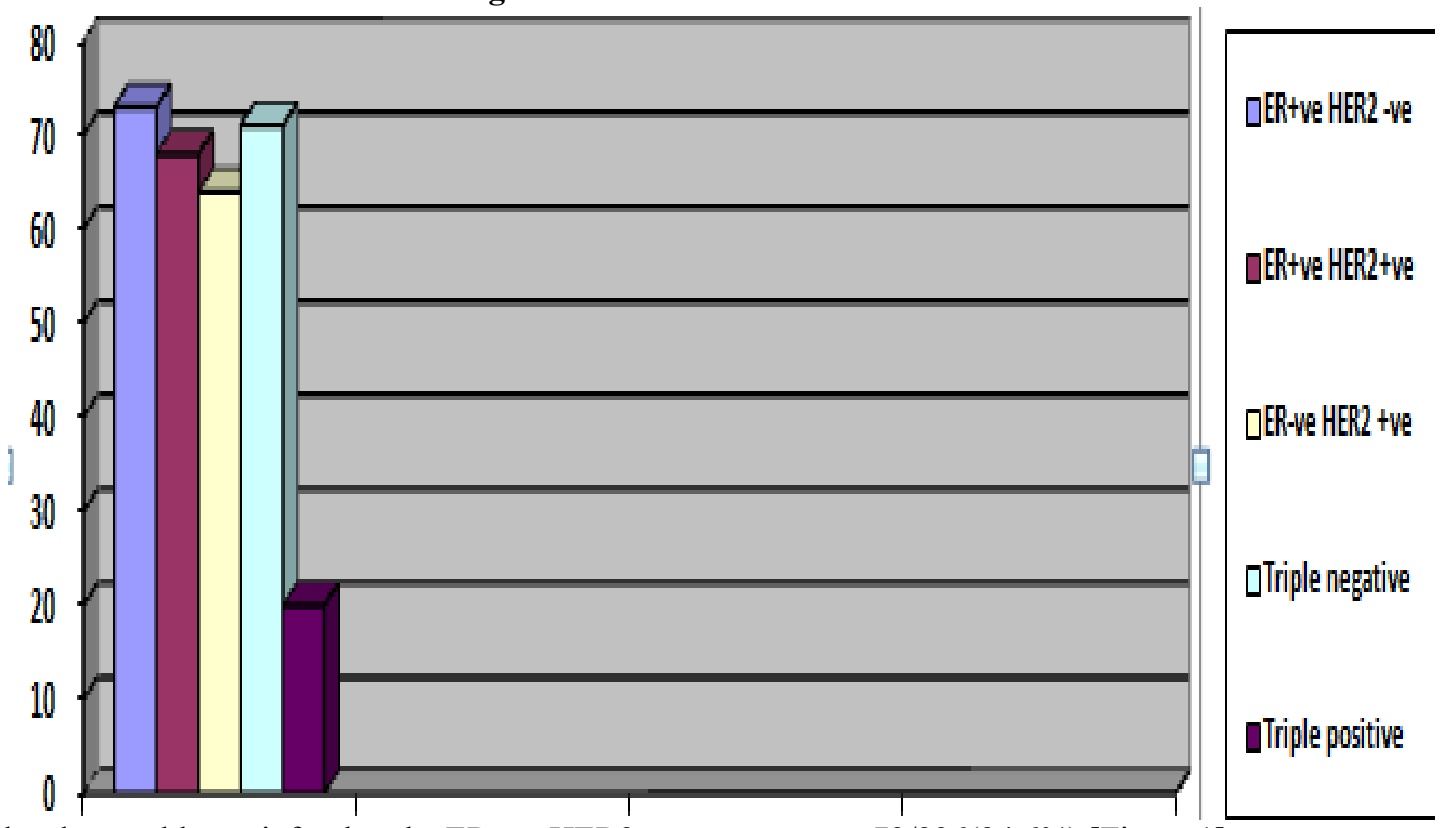

From the above table we infer that the ER+ve HER2 -ve tumor were 73/296(24.6\%) [Figure.1]

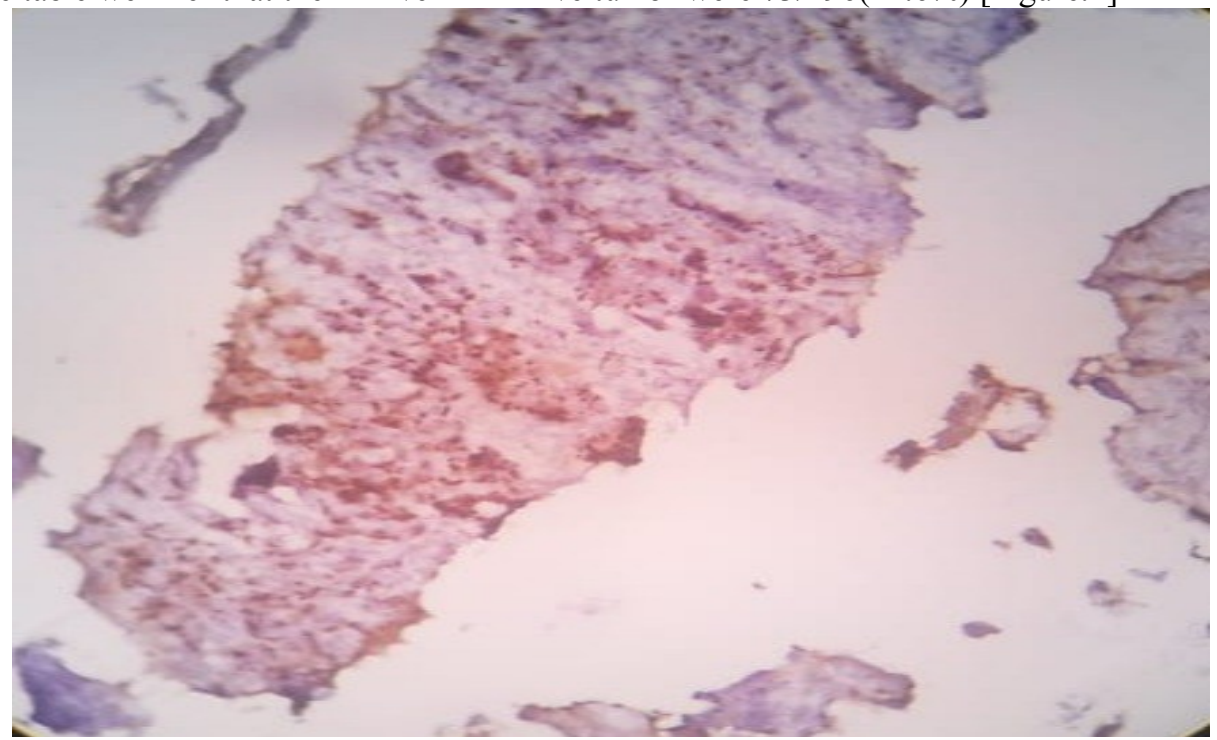

Figure 1:- ER Expression-Invasive carcinoma breast , A nest of tumor cells showing intense nuclear staining , ( IHC Stain), X 40.

ER+ve HER2 -ve were 68/296 cases. ER-ve HER2 +ve were 64/296 cases(21.6\%)[Figure.2] 


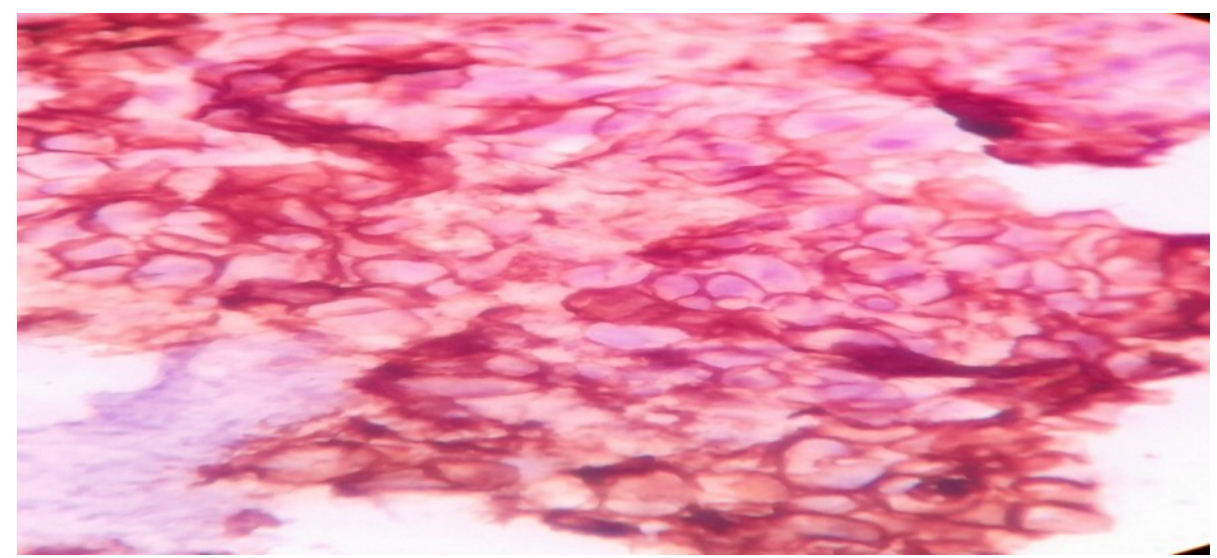

Figure 2:- Invasive carcinoma breast, The highly atypical hyperplastic cells overexpress with HER $\widehat{2}$ /neu showing the intense and circumferential cell membrane staining, ( IHC Stain) ,X 40.

Triple negative tumor cases were 71/296(23.9\%) and triple positive cases were 20/296 (6.75\%).

The pure ER positivity in $141 / 296$ cases $47.6 \%$,PR positivity in $69 / 296$ cases (23.3\%) whereas HER2 neu positivity cases 132/296 cases (44.5\%). In our present study, both ER and PR positivity was found in 66 cases(22.2\%) and both negative status in 70 cases $(23.6 \%)$.

We analysed age wise distribution of expression pattern [Table.5].This was analysed between the age group of 2090 years. In this, the highest number of cases was found in the age group of 41-50 years, that is about 95 cases were reported . Here in this range ER+ve HER2neu +ve was 35.7\%. 84 cases were reported in the age group of 51-60 years where ER+ve and HER2 -ve was 27 (32.1\%). In the age group ranging from 31-40 years 53 cases were reported and it was found that it is expressed in all ER/PR and HER2 markers. The least number of case (1 case)was found in the age group of 81-90 years which was triple negative. This same characteristics were found in the age group of 20-30 years. Thus from the above analysis it is concluded that triple negative was found only in extreme age groups. $(20-30$ years and $80-90$ years.

Table 5:- Age wise distribution of expression pattern According to the molecular classification.

\begin{tabular}{|c|c|c|c|c|c|c|c|c|}
\hline \multirow{2}{*}{ Age } & \multicolumn{2}{|c|}{ ER+ve HER2-ve } & \multicolumn{2}{c|}{ ER+ve HER2+VE } & \multicolumn{2}{c|}{ ER-ve HER2+ve } & \multicolumn{2}{c|}{ Triple negative } \\
\cline { 2 - 9 } & $\begin{array}{c}\text { Total } \\
\text { cases }\end{array}$ & $\%$ & $\begin{array}{c}\text { Total } \\
\text { cases }\end{array}$ & $\%$ & $\begin{array}{c}\text { Total } \\
\text { cases }\end{array}$ & $\%$ & $\begin{array}{c}\text { Total } \\
\text { cases }\end{array}$ & $\%$ \\
\hline $\begin{array}{c}20-30(8 \\
\text { cases) }\end{array}$ & 0 & $0 \%$ & 2 & $25 \%$ & 2 & $25 \%$ & 4 & $50 \%$ \\
\hline $\begin{array}{c}31-40(53 \\
\text { cases) }\end{array}$ & 14 & $26.4 \%$ & 13 & $24.5 \%$ & 13 & $24.5 \%$ & 13 & $24.5 \%$ \\
\hline $\begin{array}{c}41-50(95 \\
\text { cases) }\end{array}$ & 17 & $17.8 \%$ & 34 & $35.7 \%$ & 21 & $22.1 \%$ & 23 & $24.2 \%$ \\
\hline $\begin{array}{c}51-60(84 \\
\text { cases) }\end{array}$ & 27 & $32.1 \%$ & 8 & $21.6 \%$ & 21 & $25.3 \%$ & 18 & $21.6 \%$ \\
\hline $\begin{array}{c}61-70(41 \\
\text { cases) }\end{array}$ & 13 & $31.7 \%$ & 10 & $24.3 \%$ & 8 & $19.5 \%$ & 10 & $24.3 \%$ \\
\hline $\begin{array}{c}71-80(14 \\
\text { cases) }\end{array}$ & 6 & $42.8 \%$ & 4 & $28.5 \%$ & 1 & $7 . \%$ & 3 & $21.4 \%$ \\
\hline $\begin{array}{c}81-90(1 \\
\text { case) }\end{array}$ & - & - & - & - & - & - & 1 & $100 \%$ \\
\hline
\end{tabular}

\section{Discussion:-}

Invasive ductal carcinoma is the largest group of malignant mammary tumors, comprising approximately $75 \%$ of mammary carcinomas. In the later WHO lexicon, the term invasive ductal carcinoma is replaced by invasive carcinoma of no special type (NST), with authors collective opinion "The use of the term DUCTAL perpetuate the traditional but incorrect concept that these tumors are derived exclusively from mammary ductal epithelium in 
distinction from lobular carcinomas, which were deemed to have arisen within the lobules, for which there is also no evidence" [4].

As a general rule, immunohistochemistry cannot and should not replace the histopathology. It is however a valuable adjunct in diagnosis of breast pathology. The American society of clinical oncology has issued consensus panel statements supporting the use of a three- tiered categorization of ER staining percentages that acknowledges the existence of both "positive" and "low positive" cases. Additionally, the National Institute of Health concensus statement on Adjuvant Therapy for Breast cancer also states that "any degree of ER nuclear staining detected by immunohistochemistry should be considered a positive result"[5-6].

Using IHC with monoclonal antibody against HER-2/neu receptor, a positive result is interpreted as $3+$ which is characterized by strong, complete cell membrane ("chicken wire") staining. While an immune score of $2+$ is defined as weak to moderate, mostly incomplete cell membrane reactivity, a score of 1+ represents a weak cytoplasmic and are incomplete cell membrane reaction. Using IHC, at least $10 \%$ tumor cells should reveal a score of $3+$ in order to be reported as HER2/neu over expression [7].

Global gene expression profiling of breast cancer has demonstrated that invasive carcinoma breast no special type tumor can be classified into subtypes on the basis of expression pattern. At least 3 main molecular classes have been identified: Luminal/ER+ (60-70\%), HER2+ (15-20\%), Basal-like/triple negative (15-20\%) [8]. But in our study ER+ luminal type was $47.5 \%$. HER2 +ve tumor was $22.9 \%$ and triple negative tumor was $23.9 \%$. While comparing our study with the statement given by David J.Dabbs, the molecular pattern differed by showing an increase in the incidence of HER2+ and triple negative tumor.

A prevalence of $32.6 \%$ for ER+ve and $46.1 \%$ for PR+ve breast cancer has been documented in a study carried out in India [9]. In our study the PR positivity rate was $34.12 \%$ which was less when compared with the reference given [9]. Many study reports showed that the expression of hormone receptors increased in age group of the patient [1015]. In our study the ER expression is increased in higher age group and is better correlated with our study.

As the age increased, the percentage of women with ER+ve/HER2 -ve subtype also increased [16]. It is well correlated with our study. In comparison with the ER+ve, HER2 +ve and triple negative subtypes as age increased the percentage of cases decreased [16]. This is a contrast feature in our study. In both extremities of ages Triple negative tumor was in higher percentage.

\section{Significance of luminal cancer:}

Luminal tumors are reminiscent of "Normal luminal epithelial cells" including CK8/18+. Lum A are ER+ve and are enriched with genes associated with active ER pathway, low levels of proliferation related genes, low histological grade and generally good prognosis. The Lum B tumors are high grade with high proliferative index and worst outcome [17].

\section{Significance of HER2+ve tumor:}

The most promising and useful findings are based on recent studied showing HER2+ve cancers respond favorably to new antibodies based therapies, targeting specifically the HER2 protein, such a Transtuzumab [18-19].

\section{Significance of basal-like cancer:}

The basal-like subtype more commonly occurs in younger individuals [20]. Our age group also follows such pattern. The tumor usually shows high response to cytotoxic chemotherapy, although the majority relapses and the overall prognosis is very poor [20].

\section{Conclusion:-}

Breast malignancy is the most common malignant tumor and the second most common cause of carcinoma death in women. In conclusion, the marker status of ER/PR and HER2/neu is gold standard for all breast malignancy for the purpose of diagnosis, prognosis and therapy.

\section{Acknowledgements:-}

None. 


\section{Funding}

None.

\section{Competing Interests}

None Declared.

\section{References:-}

1. Rosai And Ackerman's surgical pathology .2018; Eleventh ed.Vol II, Elsevier; Philedelphia . Pg 1464-65

2. Banyameen Mohamad Iqbal, Archana Buch .Hormonal receptor ( ER, PR, HER2/neu) status and proliferation index marker(ki-67) in breast cancer; Their Onco-pathological correlation, short comings and future trends. Medical Journal of Dr.D .Y. Paul University/ published wolters kluwer - Medknow. 2020;42:111 -161.

3. Cherry Bansal et al.Correlation of Hormone Receptor and Humen Epidermal Growth factor Receptor -2/neu Expression in Breast cancer with various pathological features. Indian Journal of medical and paediatric oncology. 2017;38:483-489.

4. 4. Syad A Hoda, Edi Brogi, Fredrick C Koerner, Paul Peter Rosen. Rosen’s Breast Pathology.

5. 2014 ; Fourth ed. Wolters kluwer ; philadelphia: pg 413.

6. Allred C,HarveyJM,BeradoM,etal.Prognostic and predictive factors in breast cancer by immunohistochemical analysis.ModPathol 1999;11:155-168.

7. GoldhirschA,GlickJH,GelberRD, etal.Meeting highlights: International Consensus Panel on the Treatment of Primary Breast Cancer. Seventh International Conference on Adjuvant Therapy of Primary Breast Cancer.J Clin Oncol 2001;19:3817-3827

8. Farid Moinfar . Essentials of Diagnostic Breast Pathology, A practical Approach. 2007; springer, Newyork .pg 473-475.

9. David J. Dabbs Breast Pathology. In ( Invasive Ductal carcinoma of no special type and histological grade) : 2012; Elsevier, Philadelphia . pg 434.

10. Deepti Gupta et al. Correlation of Hormone Receptor Expression with Histologic Parameters in Benign and Malignant Breast Tumors. Iranium Journal of Pathology (2015);10 : 23-34.

11. Fisher ER, Redmond CK, Liu H, Rockette H, Fisher B. Correlation of estrogen receptor and pathologic characteristics of invasive breast cancer. Cancer.1980;45:349-53.

12. Huang WY, Newman B, Millikan RC, Schell MJ,Hulka BS, Moorman PG. Hormone - related factors and risk of breast cancer in relation to estrogen receptor and progesterone receptor status. AmJ Epidemiol .2000;151(7):703-14.

13. Fatima S, Faridi N, Gill S. Breast cancer: steroid receptors and other prognostic indicators. J Coll

14. Physicians Surg Pak 2005;15(4):230-3.

15. Rosenberg LU, Einarsdo' ttir K, Friman EI, Wedren S, Dickman PW, Hall P, et al. Risk factors for hormone receptor-defined breast cancer in postmenopausal women. Cancer Epidemiol Biomarkers Prev $.2006 ; 15(12): 2482-8$

16. . Dunnwald LK, Rossing MA, Li CI. Hormone receptor status, tumor characteristics, and prognosis: a prospective cohort of breast cancer patients. Breast Cancer Res 2007;9(1):1-10.

17. Azizun-Nisa, Bhurgri Y, Raza F, Kayani N. Comparison of ER, PR and HER-2/neu (C-erb B 2)

18. reactivity pattern with histologic grade, tumor size and lymph node status in breast cancer. Asian Pac J Cancer Prev 2008;9(4):553-6.

19. 16. Carol. A Parise, Vincent Caggiano.Breast Cancer survival Defined by ER/PR/HER2 subtypes and a surrogate classification According to tumor Grade and Immunohistochemical Biomarkers. Journal of Epidemiology(2014);26.

20. 17. Engel RH, Kaklamani VG. HER2-positive breast cancer: current and future treatment strategies. Drugs. 2007; 67:1329-41.

21. 18. E lledge RM, Green S, Pugh R, et al. Estrogen receptor (ER) and progesterone receptor (PR), by ligandbinding assay compared with ER, PR and pS2, by immunohistochemistry in predicting response to tamoxifen in metastatic breast cancer: a Southwest Oncology Group Study. Int J Cancer. 2000;89:111-7.

22. 19.Abd El-Rehim DM, Pinder SE, Paish CE, et al. Expression of luminal and basal cytokeratins in human breast carcinoma. J Pathol. 2004;203:661-71.

23. 20. Liang Cheng, John N Eble .Molecular Surgical Pathology .2013; spinnger, Newyork .pg 112. 